\title{
Applicability of an integrated plume rise model for the dispersion from wild-land fires
}

\author{
J. Kukkonen ${ }^{1}$, J. Nikmo ${ }^{1}$, M. Sofiev ${ }^{1}$, K. Riikonen ${ }^{1}$, T. Petäjä ${ }^{2}$, A. Virkkula ${ }^{1,2}$, J. Levula ${ }^{3}$, S. Schobesberger ${ }^{2}$, and \\ D. M. Webber ${ }^{4}$ \\ ${ }^{1}$ Finnish Meteorological Institute, Erik Palménin aukio 1, 00101, Helsinki, Finland \\ ${ }^{2}$ Department of Physics, University of Helsinki, 00014, Helsinki, Finland \\ ${ }^{3}$ Hyytiälä Forestry Field Station, University of Helsinki, 35500, Korkeakoski, Finland \\ ${ }^{4}$ Integral Science and Software Ltd, 484 Warrington Rd, Culcheth, Warrington WA3 5RA, UK
}

Correspondence to: J. Kukkonen (jaakko.kukkonen@fmi.fi)

Received: 16 December 2013 - Published in Geosci. Model Dev. Discuss.: 16 January 2014

Revised: 17 September 2014 - Accepted: 1 October 2014 - Published: 13 November 2014

\begin{abstract}
We have presented an overview of a mathematical model, BUOYANT, that was originally designed for the evaluation of the dispersion of buoyant plumes originated from major warehouse fires. The model addresses the variations of the cross-plume integrated properties of a buoyant plume in the presence of a vertically varying atmosphere. The model also includes a treatment for a rising buoyant plume interacting with an inversion layer. We have compared the model predictions with the data of two prescribed wild-land fire experiments. For the SCAR-C experiment in Quinault (US) in 1994, the predicted vertical extents of the plume at maximum plume rise were between 500 and $800 \mathrm{~m}$ and between 200 and $700 \mathrm{~m}$, using two alternative meteorological data sets. The corresponding observed injection heights of the aerosol particles measured using an airborne lidar (light detection and ranging) ranged from 250 to $600 \mathrm{~m}$. For the prescribed burning experiment in Hyytiälä (Finland) in 2009, the model predictions were compared with plume elevations and diameters, determined based on particulate matter number concentration measurements onboard an aeroplane. However, the agreement between modelled and measured results substantially depends on how the properties of the source term are evaluated, especially regarding the convective heat fluxes from the fire. The results demonstrate that in field experiments on wild-land fires, there are substantial uncertainties in estimating both (i) the source terms for the atmospheric dispersion computations and (ii) the relevant vertical meteorological profiles.
\end{abstract}

\section{Introduction}

Both fires in warehouses and wild-land fires (the latter include, for example, heath, moorland and forest fires) may represent a major hazard or health effect to/on people and the environment, and the fire plumes may contain a variety of harmful or toxic chemical compounds. The initial vertical distribution of pollutants originating from a fire is controlled by strong updraughts associated with the buoyancy of fire emissions. The pollutants may be transported to the upper part of the atmospheric boundary layer (ABL), to the free troposphere and in some cases to the stratosphere (e.g. Freitas et al., 2007; Sofiev et al., 2012). The composition of effluents from fires and their atmospheric distribution depends on the burned material, processes near the fire, and larger-scale atmospheric processes. A crucial near-fire process is the initial plume rise that determines the injection height of the fire plume (e.g. Liousse et al., 1996; Trentmann et al., 2002).

There are several types of methods for evaluating the injection height of wild-land fire plumes: (i) prescribed vertical emission profiles (e.g. Davison, 2004; Forster et al., 2001; Liousse et al., 1996); (ii) semi-empirical plume rise models, such as that presented by Sofiev et al. (2012); and (iii) cross-plume integrated plume rise models (e.g. Wigley and Slawson, 1971; Martin et al., 1997; Kukkonen et al., 2000). Recently, Devenish et al. (2010) presented largeeddy simulation (LES) results of buoyant plumes in a crossflow. Comprehensive overviews of buoyant plume models and their history are presented in, for example, Devenish et al. (2010) and Jirka (2004). 
Many plume rise models currently in use are cross-plume integrated plume rise models, which consider the conservation of bulk quantities (mass, momentum and enthalpy) integrated over the plume cross section, with the system of equations closed using an entrainment assumption. The entrainment assumption relates the mean entrainment inflow velocity to the mean plume velocity (Middleton, 1986). Development of these models was originally based on the analysis of Morton et al. (1956), extended to include the effects of vertically varying atmospheric profiles (e.g. Martin et al., 1997).

The plume rise model presented in this paper was originally developed for the EU-funded project "Dispersion from strongly buoyant sources - BUOYANT" (1994-1997), which addressed the atmospheric dispersion of pollutants originated from fires in warehouses and chemical stores. The main objectives of this project were (i) to develop a mathematical model of a plume designed for conditions of very high buoyancy; (ii) to generate a carefully designed set of experimental data for the high-buoyancy, near-field region; and (iii) to validate the model against existing data. An overview of this project and its achievements is presented in Kukkonen et al. (2000) and Ramsdale et al. (1997). A more detailed description of the modelling of plume rise and near-field dispersion is reported in Martin et al. (1997), and the modelling of the larger-scale dispersion was addressed by Nikmo et al. $(1997,1999)$.

The first aim of this article is to present an overview of the current version of the model called BUOYANT, the original version of which was developed within the above-mentioned project. The model structure has not previously been published in reviewed literature. Although the model has originally been developed for the evaluation of fire plumes from warehouses and chemical stores, we also aim to evaluate the model performance for plumes originated from wild-land fires. Major wild-land fires can produce substantially more extensive and intensive fire plumes, compared with characteristic warehouse fires. Our aim is also to discuss both the advantages and limitations of the presented cross-plume integrated model.

The second aim of the article is to compare the model predictions against two experimental field data sets of prescribed wild-land fires. These are the "Smoke, Clouds and Radiation - California" experiment (SCAR-C) in Quinault in the US in 1994 (e.g. Kaufman et al., 1996; Hobbs et al., 1996; Gassó and Hegg, 1998) and an experiment in Hyytiälä in Finland in 2009 (Virkkula et al., 2014a, b; Schobesberger et al., 2013). We have also compared the predictions of a simple semi-empirical model of Sofiev et al. (2012) with the measurements of the above-mentioned two prescribed fires, and with the predictions of the BUOYANT model.

Clearly, the comparison of model predictions with the data of only two atmospheric dispersion cases cannot constitute any complete or conclusive evaluation of the model. There are several major challenges in measuring the detailed source properties and the meteorological conditions in such field experiments. Our aim is therefore to illustrate these challenges and uncertainties in estimating the source terms and the atmospheric conditions for estimating the plume rise; this is expected to be useful for planning of prescribed burning experiments in the future.

\section{Materials and methods}

\subsection{The modelling of emissions, plume rise and atmospheric dispersion}

\subsubsection{The overall structure of the BUOYANT model}

The model includes treatments (i) for near- and intermediatefield dispersion of the plume, including the plume rise computations, and (ii) for dispersion after the plume rise regime. The larger-scale dispersion is of particular importance for highly toxic substances. These sub-models constitutes a computer code called BUOYANT, which can be used by hazard analysts to predict the concentration of toxics at different distances from a highly buoyant source, such as a large fire.

The sub-model after the plume rise regime is described in detail in Nikmo et al. (1997, 1999). After the plume rise, but in the vicinity of the source, Gaussian equations are used in both the horizontal and vertical directions. After a specified transition distance, gradient transfer $(K-)$ theory is applied in the vertical direction, while the horizontal dispersion is still assumed to be Gaussian.

The near- and intermediate-dispersion module of the BUOYANT program addresses the behaviour of a buoyant plume in the presence of a wind. The model equations allow for the variation in the relevant atmospheric properties with height. The model also includes a treatment for the case of a rising buoyant plume encountering an inversion layer. Buoyancy is gradually depleted as the plume interacts with the inversion layer, and the plume may run out of buoyancy while some material is still within the mixing layer. Alternatively, the plume may be sufficiently buoyant to fully penetrate the inversion layer (Martin et al., 1997).

In this article, we address in detail only the currently available BUOYANT model treatments for the near- and intermediate-field dispersion. Compared with the original model version for this regime (Martin et al., 1997), we have (i) revised the equations for the meteorological vertical profiles in stable conditions in order for them to be based on more up-to-date results, (ii) corrected an inaccuracy in the formulation in the entrainment closure equation, and (iii) revised the criterion for the termination of the plume rise in the model in order for it to be simpler than the original assumptions. Otherwise, the model equations are the same as in the original model formulation. For technical reasons, the model for the near- and intermediate-field dispersion has also been coded again at the Finnish Meteorological Institute. 
The model contains three parameters that need to be experimentally determined. However, we have simply used the values that were determined previously in wind tunnel experiments (e.g. Kukkonen et al., 2000). The model therefore contains no freely adjustable parameters.

\subsubsection{Previous evaluations of the BUOYANT model against experimental data}

The plume rise sub-model of the original version of the BUOYANT model has been evaluated against the experimental data generated by the University of Hamburg in their wind tunnel facility. The results of the model evaluation in the wind tunnel facility have been presented by Liedtke and Schatzmann (1997), and reviews of this model evaluation by Martin et al. (1997) and Kukkonen et al. (2000). The wind tunnel simulations were conducted both in unstratified boundary layers and in the presence of an elevated inversion. The overall agreement between model predictions and measured data was good. One of the experimental data sets was used to determine best estimates for three parameters which appear in the buoyant plume rise model (Martin et al., 1997).

The BUOYANT sub-model after the plume rise regime has been tested against the Kincaid experimental field data (Olesen, 1995). The average agreement between the predictions and the data was reasonably good (Kukkonen et al., 2000).

Recently, Sofiev et al. (2012) compared the BUOYANT plume rise model predictions against a data set collected using the Multi-angle Imaging SpectroRadiometer (MISR) Plume Height Project (Diner et al., 1998; Mazzoni et al., 2007; Kahn et al., 2008). In this project, measured data were collected for about 2000 fire plumes in North America and Siberia during the fire seasons in 2007 and 2008. The predictions of the BUOYANT model (the same model version as used in this study), as well as those obtained using a semi-empirical plume rise model, were compared with remote sensing observations of the plume top. Overall, the BUOYANT model provided for fairly reliable predictions in comparison with the measured data. For example, more than half of the model predictions were within the uncertainty of the observations $( \pm 500 \mathrm{~m})$ compared with the measured values. However, the model slightly underestimated the observed plume tops; one possible reason for this could be that the model does not allow for the influence of water vapour condensation.

\subsubsection{The model input data}

The model requires input concerning the meteorological conditions, the source term and the model parameters. The meteorological input includes the following: the Monin-Obukhov length, the height of mixing layer, the roughness lengths of heat and momentum transfer, the air temperature, the pressure and wind speed at a reference height, the height of the inversion layer (above the mixing layer), the potential temperature gradient within the inversion layer, and the wind speed and potential temperature gradient above the inversion layer.

Information on the source term includes the following: the source radius, the source height above the ground, the temperature of the released mixture of contaminant gas (and particles) and air, the mass flux of this mixture, the mass fraction of the released gas, and the molecular weight and heat capacity of the released gas. The model parameters, the values of which may be set by the user, are the entrainment coefficients $\left(\alpha_{1}, \alpha_{2}\right)$ and the added mass term $\left(k_{v}\right)$.

\subsubsection{Modelling of the source term: mass and heat fluxes originated from fires}

Let us first address the relations of the source term parameters. The further evolution of the plume, including the vertical structure of the atmosphere; the entrainment of air; the fluxes of mass, momentum and heat; and the penetration of inversion layers are described in the following sections.

The parameters of the source term for the dispersion modelling were determined with a simple integral approach. Assuming that plume gases have similar specific heat capacities and molecular mass values to hot air, the mass flux from the fire can be simply estimated as (e.g. Fisher et al., 2001)

$q=v A \rho$,

where $v$ is the vertical velocity of the gas mixture, $A$ is the horizontal area of the source and $\rho$ is the density of air.

The convective heat flux is modelled as

$Q_{c}=c_{p} q\left(T-T_{\mathrm{amb}}\right)$,

where $c_{p}$ is the specific heat of gas, $T$ is the temperature of the gas and $T_{\mathrm{amb}}$ is the ambient temperature.

\subsubsection{Modelling of the plume rise and near field dispersion}

The BUOYANT model is applicable for steady-state buoyant plumes within a vertically varying atmosphere, i.e. wind speed, ambient temperature, pressure and density vary with height. The atmosphere surrounding the plume is assumed to be undisturbed by the source, i.e. its characteristics are not affected by the heat released from the source.

The model also includes a treatment for the plume encountering a temperature inversion above the atmospheric boundary layer. Buoyancy is gradually depleted as the plume interacts with the inversion layer, and the plume may run out of buoyancy while some of the material is still within the mixing layer. Alternatively, the plume may be sufficiently buoyant to fully penetrate the inversion layer. 
Vertical profiles of wind speed, temperature, pressure and density in the atmosphere

The model allows for the use of a wide range of atmospheric vertical profiles. It is possible to use either measured profiles or those predicted, for example, by a numerical weather prediction model. However, these profiles cannot contain too abrupt changes vertically; this would mean that, in a given cross section of the plume, one set of meteorological quantities would not be representative.

In the following we present a method that is valid in most cases for estimating atmospheric profiles and is simple to use computationally and in terms of input data. The vertical structure of the atmosphere is assumed to comprise three distinct layers: the atmospheric boundary layer (ABL), capping inversion layer and upper layer. In the lowest layer (ABL) the vertical variations of wind speed $(u)$ and potential temperature $(\theta)$ are assumed to be described with profiles based on the Monin-Obukhov similarity theory (e.g. Garratt, 1994):

$u(z)=\frac{u_{*}}{\kappa}\left(\ln \left(\frac{z}{z_{0}}\right)-\psi_{\mathrm{m}}(\xi)+\psi_{\mathrm{m}}\left(\xi_{0}\right)\right)$,

$\theta(z)-\theta\left(z_{0 \mathrm{~h}}\right)=\frac{\theta_{*}}{\kappa}\left(\ln \left(\frac{z}{z_{0 \mathrm{~h}}}\right)-\psi_{\mathrm{h}}(\xi)+\psi_{\mathrm{h}}\left(\xi_{0 \mathrm{~h}}\right)\right)$,

where $z$ is the height above ground, $u_{*}$ is the friction velocity, $\kappa$ is the von Karman constant, $z_{0}$ is the roughness length of momentum, $\psi_{\mathrm{m}}$ and $\psi_{\mathrm{h}}$ are the influence functions of mass and heat, $\xi=z L^{-1}$ is the dimensionless height (thermal stability parameter), $L$ is the Monin-Obukhov length, $\xi_{0}=z_{0} L^{-1}, \theta_{*}$ is the temperature scale, $z_{0 \mathrm{~h}}$ is the roughness length of heat and $\xi_{0 \mathrm{~h}}=z_{0 \mathrm{~h}} L^{-1}$.

For the influence functions in unstable conditions $(L<0)$, we apply the commonly accepted expressions (usually referred to as Businger-Dyer profiles)

$$
\begin{aligned}
\psi_{\mathrm{m}}(\xi) & =2 \ln \left(\frac{1+Y}{2}\right)+\ln \left(\frac{1+Y^{2}}{2}\right) \\
& -2 \tan ^{-1} Y+\frac{\pi}{2}, \\
\psi_{\mathrm{h}}(\xi) & =2 \ln \left(\frac{1+\left(1-\gamma_{\mathrm{h}} \xi\right)^{1 / 2}}{2}\right),
\end{aligned}
$$

where $Y=\left(1-\gamma_{\mathrm{m}} \xi\right)^{1 / 4}$, and for the constants we apply the values proposed by Brutsaert (1982), i.e. $\gamma_{\mathrm{m}}=\gamma_{\mathrm{h}}=16$.

For stable conditions $(L>0)$, we use the expressions proposed by Beljaars and Holtslag (1991):

$$
\begin{aligned}
\psi_{\mathrm{m}}(\xi) & =-a \xi-b\left(\xi-\frac{c}{d}\right) \exp (-d \xi)-\frac{b c}{d} \\
\psi_{\mathrm{h}}(\xi) & =-\left(1+\frac{2}{3} a \xi\right)^{3 / 2}-b\left(\xi-\frac{c}{d}\right) \exp (-d \xi) \\
& -\frac{b c}{d}+1
\end{aligned}
$$

where the constant $a=1, b=0.667, c=5$ and $d=0.35$. The previous version of the BUOYANT model used wind speed and temperature profiles according to van Ulden and Holtslag (1985) and Paulson (1970). The two above equations, Eqs. (7) and (8), take into account the different efficiencies between the exchange of heat and momentum in the intermittent regime, while avoiding the total vanishing of turbulence in very stable conditions (Blümel, 2000).

In the upper layer, the wind speed is assumed to be constant (representing the geostrophic flow), whereas within the inversion layer the wind speed is assumed to change with constant gradient from its value at the top of the ABL to the geostrophic value (the constant value within the upper layer). The inversion layer has a constant potential temperature gradient. The upper layer may have a potential temperature gradient that is zero or positive (albeit smaller than in the inversion layer).

Pressure and density of air are obtained by employing the hydrostatic assumption, i.e. the force of gravity is balanced by the vertical component of the atmospheric pressure gradient force (Martin et al., 1997). The turning of the wind with height has been ignored, i.e. the plume centre line trajectory is assumed to lie in a vertical plane. The model also does not allow for the influence of atmospheric humidity.

\section{The fluxes of mass, momentum and heat of the plume}

For readability, we present here an overview of the plume equations within a varying atmosphere. For a more detailed description, the reader is referred to Martin et al. (1997).

The source is assumed to be circular and horizontal. The gases at the source consist of a mixture of dry air and contaminant gas. Changes in phase (condensation of vapour or evaporation of liquid) are not handled. The plume is allowed to have buoyancy both by virtue of having a higher temperature than its surroundings and because it contains a gas of different molecular weight than that of air. The mixture is assumed to have only vertical velocity at the source. The source is assumed to persist for a sufficient length of time so that the plume achieves a steady-state behaviour.

The plume is assumed to remain axially symmetric as it rises. The radial variation in quantities of interest will be assumed to be described by a "top-hat" profile. The contaminant gas is assumed not to react with the air or change its state from gas. The ordinary differential equations describing the plume will be derived by considering the rate of change of (integral) fluxes along the plume. These equations include those for the fluxes of mass, momentum and heat, closed by an entrainment assumption.

The mass flux change due to entrainment of air is given by

$\frac{\mathrm{d} q}{\mathrm{~d} s}=2 \pi r \rho_{\mathrm{a}} u_{\mathrm{e}}$,

where $s$ is the distance along the plume centre line trajectory, $r$ is the radius of the plume in the direction normal to the 
plume axis, $\rho_{\mathrm{a}}$ is the density of ambient air and $u_{\mathrm{e}}$ is the entrainment velocity.

The model employs an entrainment closure approach that distinguishes between the separate contributions of transverse shear (leading to jet, plume, or wake internal flow dynamics) and of azimuthal shear mechanisms (leading to advected momentum puff or thermal flow dynamics), respectively

$$
\begin{aligned}
u_{\mathrm{e}} & =\alpha_{1}\left(\frac{\rho}{\rho_{\mathrm{a}}}\right)^{0.5}\left|u-u_{\mathrm{w}} \sin (\alpha)\right| \\
& +\alpha_{2}\left(\frac{\rho}{\rho_{\mathrm{a}}}\right)^{0.5} u_{\mathrm{w}}|\cos (\alpha)|,
\end{aligned}
$$

where $\alpha_{1}$ and $\alpha_{2}$ are the along and cross-plume air entrainment coefficients, respectively; $\rho$ is the mean density of the plume; $u$ is the mean velocity along the plume centre line; $u_{\mathrm{w}}$ is the wind speed; and $\alpha$ is the angle between the direction of the plume and the vertical. We have applied the values for the air entrainment coefficients determined based on wind tunnel experiments, i.e. $\alpha_{1}=0.08$ and $\alpha_{2}=0.7$ (Martin et al., 1997).

We have written the cross-plume entrainment term using an absolute value of $\cos (\alpha)$; this was not the case for the original formulation of the model by Martin et al. (1997). However, both the entrainment terms need to be positive to be physically meaningful. The cross-plume entrainment term in the original formulation becomes negative for oscillating plumes during the descending plume motion (i.e. for $\alpha>90^{\circ}$ ).

The first term on the right-hand side of Eq. (10) represents the entrainment of air due to the velocity difference between the plume and the air along the plume direction. This term is referred to as along-plume entrainment. The second term represents cross-plume entrainment, which is zero in calm air. The entrainment assumption takes the same form whether the plume is rising vertically or is close to horizontal (bentover plumes).

The form of the entrainment terms is after Ricou and Spalding (1961). This differs from the Morton and Taylor entrainment velocity (Morton et al., 1956) by the inclusion of the square root of the density ratio. The selection between these two entrainment models is important for plumes that have a density that differs substantially from ambient air density. However, there is no conclusive experimental evidence regarding which of these two models would be preferable.

The rate of change of horizontal $\left(\varphi_{x}\right)$ and vertical $\left(\varphi_{z}\right)$ momentum fluxes are

$$
\begin{aligned}
\frac{\mathrm{d} \varphi_{x}}{\mathrm{~d} s} & =\frac{\mathrm{d} q}{\mathrm{~d} s} u_{\mathrm{w}} \\
\frac{\mathrm{d} \varphi_{z}}{\mathrm{~d} s} & =\frac{\pi r^{2} g\left(\rho_{\mathrm{a}}-\rho\right)}{1+k_{v} \sin (\alpha)},
\end{aligned}
$$

where $g$ is the acceleration due to gravity and $k_{v}$ is an adjustable coefficient (of order 1). The denominator of the vertical momentum flux equation is a term for added mass included to account for the plume having to push air out of the way as it rises; this term has been written by analogy to the behaviour of a line thermal (Martin et al., 1997). The term including $k_{v}$ is commonly called the added mass term. Theoretically, the possible values of $k_{v}$ range from 0.0 to 1.0. We have adopted the value $k_{v}=1.0$, based on comparisons of model predictions and wind tunnel experiments (Martin et al., 1997). There is no drag term in the momentum equation.

The change in horizontal and vertical excess momentum fluxes (due to the vertical gradient of the wind speed) are

$$
\begin{aligned}
\frac{\mathrm{d} \varphi_{x}^{e}}{\mathrm{~d} s} & =-\frac{\overline{\mathrm{d} u_{\mathrm{w}}}}{\mathrm{d} z} q \cos (\alpha) \\
\frac{\mathrm{d} \varphi_{z}^{e}}{\mathrm{~d} s} & =\frac{\mathrm{d} \varphi_{z}}{\mathrm{~d} s},
\end{aligned}
$$

where $\overline{\mathrm{d} u_{\mathrm{w}} / \mathrm{d} z}$ is the mean representative wind speed gradient. The plume equations are derived on the assumption that the gradients in ambient atmospheric properties are constant across the plume cross section.

In considering the behaviour of a rising plume contacting an elevated inversion, the mean representative wind speed gradient is an area-weighted average defined as

$\frac{\overline{\mathrm{d} u_{\mathrm{w}}}}{\mathrm{d} z}=\sum_{i=1}^{3}\left(\frac{\mathrm{d} u_{\mathrm{w}}}{\mathrm{d} z}\right)_{i} f_{i}$,

where $\left(\mathrm{d} u_{\mathrm{w}} / \mathrm{d} z\right)_{i}$ is a representative value for the portion of plume within the $i$ th layer and $f_{i}$ is the fraction of plume cross-sectional area lying in the $i$ th layer.

The rate of change of the excess enthalpy flux is given by

$\frac{\mathrm{d} H^{e}}{\mathrm{~d} s}=-\frac{\overline{\mathrm{d} \theta_{\mathrm{a}}}}{\mathrm{d} z} \cos (\alpha) c_{\mathrm{pa}}\left(q+\left(\frac{c_{\mathrm{pg}}}{c_{\mathrm{pa}}}-1\right) S\right)$,

where $\theta_{\mathrm{a}}$ is the potential temperature of ambient air; $c_{\mathrm{pa}}$ and $c_{\mathrm{pg}}$ are the specific heat capacities of air and released substance, respectively; and $S$ is the constant contaminant flux. The mean representative gradient of $\theta_{\mathbf{a}}$ is defined analogously to the mean wind speed gradient, Eq. (13). The trajectory of the plume is obtained from the following simple kinematic relationships:

$$
\begin{aligned}
& \frac{\mathrm{d} x}{\mathrm{~d} s}=\sin (\alpha) \\
& \frac{\mathrm{d} z}{\mathrm{~d} s}=\cos (\alpha),
\end{aligned}
$$

where $x$ is the downwind distance from the source.

The model has three experimentally adjustable parameters: along- $\left(\alpha_{1}\right)$ and cross- $\left(\alpha_{2}\right)$ plume entrainment coefficients, and the coefficient for the added mass term $\left(k_{v}\right)$. We have set the values of the plume entrainment coefficients based on wind tunnel measurements, and a default value of unity has been used for the added mass term. The buoyant plume model has no remaining adjustable parameters. 


\subsubsection{Criterion for the termination of plume rise}

The determination of the final plume rise presents a number of challenges, as discussed by, for example, Devenish et al. (2010). The observed behaviour of a buoyant plume shows that in some cases the plume simply approaches a final rise height at some distance downwind. At this distance, both the buoyancy force and the vertical momentum vanish. The same behaviour is demonstrated by model simulations.

However, in some other situations, model computations show that during the initial rise the buoyancy force acting on it may fall to zero. The plume does not immediately stop rising, since it will have some upward momentum. The upward momentum will eventually vanish at maximum rise height, at which time a negative buoyancy may cause the plume to descend. In principle, the plume executes a damped harmonic oscillation, damped because the mass flux is assumed to continue increasing. The plume oscillates with decaying amplitude as it settles down to its asymptotic height. The height at which the buoyancy first becomes zero is termed here the equilibrium height.

The equilibrium height can be expected to provide an estimate of the asymptotic height. Available observations also support the use of the equilibrium height (Briggs, 1975; Martin et al., 1997). According to the computations of Martin et al. (1997), the asymptotic height attained by a bent-over plume rising in a layer of constant positive vertical potential temperature gradient is only a few percent higher than the equilibrium height. They therefore concluded that the asymptotic height of the plume is very close to the equilibrium height, and suggested the equilibrium height to be a suitable height to terminate the calculation.

In the current model version, we have chosen simply to use the equilibrium height as the final rise height of the plume. The previous model version included two additional criteria for the termination of the rise. These are (i) to terminate if the plume as a whole has penetrated the inversion layer, and (ii) to terminate if the horizontal speed of the plume is close to the ambient wind speed. The current model version does not include these two criteria, as we considered it relevant to also consider the plume behaviour after a possible penetration of an inversion layer, and in the case of very light wind speeds or calm conditions.

\subsubsection{The numerical solution}

The computer program was written in Fortran 2003. The set of ordinary differential equations that consists of Eqs. (9), (11), (12), (14) and (15), i.e. the changes of fluxes, does not have an analytical solution. This set of equations is therefore solved numerically, applying backward differentiation formulas (Gear, 1971). These have been implemented in the public domain SLATEC (1993) procedures SDRIV3/DDRIV3.
The quantities describing the properties of the plume (e.g. radius, density and temperature) can then be determined based on the values of the fluxes (Martin et al., 1997). The equation for the vertical atmospheric pressure profile was solved using a numerical integration (Martin et al., 1997).

\subsection{Prescribed burn experiments}

The SCAR-C experiment in Quinault was selected as it provides well-documented information on the fire, such as fire extent, heat release and emissions, and the measured concentrations and plume dispersion. The experiment in Hyytiälä was selected as it also provides detailed information on the fire and a wide variety of both stationary and mobile groundbased and aircraft-based concentration measurements.

\subsubsection{Overview of the SCAR-C experiment in Quinault}

The "Smoke, Clouds and Radiation - California" (SCAR-C) experiment was conducted in September 1994 in the Pacific Northwest of the United States (Kaufman et al., 1996; Hobbs et al., 1996; Gassó and Hegg, 1998). It is one of a series of SCAR experiments designed to measure the optical, physical and chemical properties of aerosol particles and their interactions with clouds and radiation. The emphasis of the SCAR-C experiments was to measure the entire process of biomass burning, including ground-based estimates of fuel consumption, airborne sampling of the smoke aerosols and trace gases, and air- and spaceborne remote sensing of both the fires and the smoke (Kaufman et al., 1996).

During SCAR-C, four prescribed and eight natural fires were observed and measured (Kaufman et al., 1996). Here we only address the prescribed fire on 21 September in the Quinault Indian Reservation. This burn was typical of large, clear-cut, prescribed burns that occur periodically along the coastal lands of the Pacific Northwest (Hobbs et al., 1996).

The fire was a 19.4 ha clear-cut burn, fuelled by dry remnants of large western red cedar debris left over from logging. The fire was ignited on 21 September 1994 at about 11:10 LT and immediately burned vigorously, continuing for about $6 \mathrm{~h}$. Estimates from ground observations of the ignition pattern and plume indicated that the maximum heat release rate probably occurred between 12:15 and 12:45 LT (Hobbs et al., 1996). At 13:00 the fire was entirely in the smouldering phase. Measurements and estimates of the burn included ground-based fuel consumption, airborne sampling of the particles and trace gases, and remote sensing of both the fire and smoke.

Vertical distribution of smoke particles was derived from the airborne lidar measurements between 12:54 and 12:59; these show that most of the smoke particles were between the heights of 250 and $600 \mathrm{~m}$, some $300 \mathrm{~m}$ downwind of the source (Hobbs et al., 1996). The plume centre line increased in height by about $350 \mathrm{~m}$, as it drifted downwind over a distance of about $25 \mathrm{~km}$. Based on the photographs taken of 
the smoke originating from the fire, Kaufmann et al. (1996) concluded that the plume had ascended into a layer just under an inversion that was located at a height of $1300 \mathrm{~m}$.

\subsubsection{Overview of the prescribed burn in Hyytiälä}

The prescribed burning experiment in Hyytiälä in southern Finland was part of both (i) the European Integrated project on "Aerosol Cloud Climate and air Quality Interactions" (EUCAARI; Kulmala et al., 2009) and (ii) the project "Integrated Monitoring and Modelling System for Wildland Fires" (IS4FIRES; Sofiev et al., 2009). A more detailed overview of the experiment and selected results is presented in Virkkula et al. (2014a); the airborne measurements are discussed in more detail in Schobesberger et al. (2013) and Virkkula et al. (2014b). The goals of the experiment were to study the aerosol chemical composition and physical characteristics, the concentrations of gaseous compounds, the detection of fires using satellite remote sensing, and the modelling of both fire spreading and atmospheric dispersion of the fire plume.

The burned site had previously been cut clear; some tree trunks, all tree tops and branches were left on the ground. The area of the burned site was $0.806 \mathrm{ha}$, and it was situated approximately $300-500 \mathrm{~m}$ south of the SMEAR II (SMEAR: Station for Measuring forest Ecosystem-Atmosphere Relations) station (Hari and Kulmala, 2005). The experiment was conducted in the morning of 26 June 2009. The burn was ignited at 08:45 LT (UTC $+3 \mathrm{~h}$ ). The flaming phase lasted for $2 \mathrm{~h} 15 \mathrm{~min}$, the smouldering phase for $3 \mathrm{~h}$.

The amount of burned organic material was approximately $46.8 \mathrm{t}$ (i.e. $58.1 \mathrm{tha}^{-1}$ ). Approximately $64 \%$ of the burned material consisted of cut tree material, $32 \%$ of organic litter and humus layer, and about $4 \%$ of surface vegetation (Virkkula et al., 2014a).

The burned area and the location of the measurement stations have been presented in Fig. 1. Stationary measurements were conducted within and in the immediate vicinity of the burned area, at the SMEAR II main building, at the SMEAR II mast, and at the so-called SMEAR II aerosol measurements cottage. In the following, the three latter ones will be collectively referred to as the SMEAR II stations.

Measurements were conducted on the ground with both stationary and mobile instrumentation, and from a Cessna FR172F aeroplane. Ground-based instrumentation included the SMEAR II stations, together with meteorological and ecological measurements on and around the site (Virkkula et al., 2014a). Ground-level measurement of particles and trace gases was also carried out by using a movable research van, and by using portable particle counters at different distances from the burning area.

The airborne measurements also addressed the spatial variability of particle number concentration within the smoke plume. The flights included aircraft ascensions up to an altitude of $4 \mathrm{~km}$ and subsequent descents close to the ground

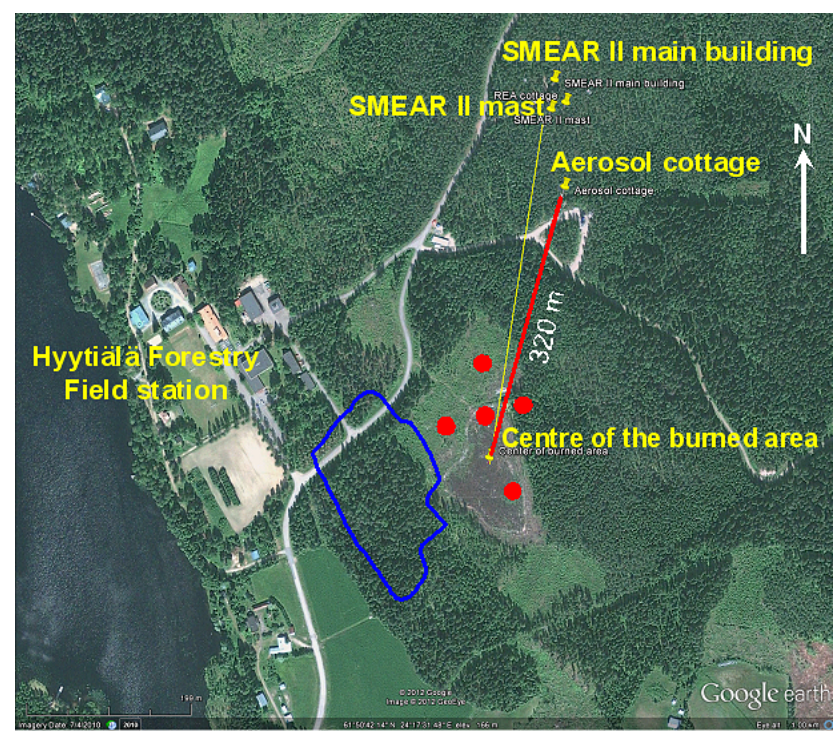

Figure 1. Location of the burned area (in grey), the SMEAR II main building, mast, and aerosol cottage (yellow pins), and the meteorological measurements within and around the burning area (red dots). The distance from the centre of the burned area to the aerosol cottage is $320 \mathrm{~m}$. The blue line encircles a non-burned reference area. This Google Earth satellite image was taken on 4 July 2010, approximately a year after the burn.

level, yielding both vertical and horizontal profiles of the measured parameters. Three measurement flights were conducted: one during the flaming phase, another during the smouldering phase and the third one after the time at which no smoke was observed at the ground level.

In total, 27 smoke plume passages were detected during the first flight. The data were saved at $1 \mathrm{~Hz}$ frequency. The ground speed of the aeroplane ranged from 106 to $199 \mathrm{~km} \mathrm{~h}^{-1}$; this corresponds to a horizontal spatial resolution of approximately $29-55 \mathrm{~m}$ for the measured airborne data. The latitude and longitude of the aeroplane was detected using an onboard GPS receiver on a time resolution of $1 \mathrm{~s}$. The altitude was obtained from the pressure altimeter of the aeroplane.

The fire temperature and vertical flow velocity were measured with a sonic anemometer installed in the middle of the burn area at a height of $10 \mathrm{~m}$ (Virkkula et al., 2014a). The data were measured at a frequency of $10 \mathrm{~Hz}$ from 08:00 to 10:39 LT. Unfortunately, as the flaming phase lasted from 08:45 to 11:00 LT, these measured values do not cover the final stages of the flaming phase. The measured ambient air temperature before the burn was approximately $294 \mathrm{~K}$. 


\section{Results and discussion}

\subsection{The SCAR-C experiment in Quinault}

\subsubsection{Evaluation of the vertical profiles of meteorological variables}

The vertical profiles of wind speed and temperature required by the model were determined both by applying the onsite measurements and the ERA-40 meteorological reanalysis data (Uppala et al., 2005). This approach will provide for an estimate on the uncertainty associated with the determination of meteorological input data for the models.

The meteorological on-site measurements were conducted onboard the Convair C-131A aeroplane before the ignition of the fire on 21 September 1994 between 11:00 and 11:11 LT (Trentmann et al., 2002). The measurements were available between the altitudes of 320 and $1890 \mathrm{~m}$.

The ERA-40 data are based on a European reanalysis of meteorological observations from September 1957 to August 2002, produced by the European Centre for MediumRange Weather Forecasts (ECMWF). The data were extracted from the data portal of the ECMWF (ERA 40, 2013). We have selected the time instant of the ERA-40 data at 11:00 LT (18:00 UTC) on 21 September 1994. In the following, we will express all times as local time.

It is not clear which of the ERA-40 grid points in the vicinity of the fire site would be best representative spatially and how much the exact location of an ERA-40 point will affect the determined meteorological profiles. We have therefore used the data at all of the four ERA-40 grid points that are closest to the measurement location. The lengths of the sides of the grid square surrounding the Quinault fire are approximately 280 and $190 \mathrm{~km}$, in the north-south and the east-west directions, respectively. The two easterly ERA-40 points are located inland, at distances of about 120 and $290 \mathrm{~km}$ from the fire; these are referred to here as continental, northern (CN) and continental, southern (CS) points. The two westerly points are situated in the Pacific Ocean, at distances of about 60 and $260 \mathrm{~km}$ from the fire; these are referred here as marine, northern (MN) and marine, southern (MS) points. The prevailing wind during the fire was easterly (Trentmann et al., 2002).

The atmospheric temperature and wind speed profiles are presented in Fig. 2a and b. These include two kinds of measured or analysed profiles: (i) those measured on-site onboard the Convair aeroplane and (ii) those based on the data at the four ERA-40 points closest to the fire. The measured onsite vertical profiles were obtained by combining airborne measurements and radiosonde observations. In addition, two modelled profiles are presented. The mathematical forms of the modelled vertical wind speed and temperature profiles are presented in Eqs. (3) and (4). The modelled profiles were based on the measured data on-site and at the CN ERA-40 point. This is the nearest ERA-40 point located inland, at an
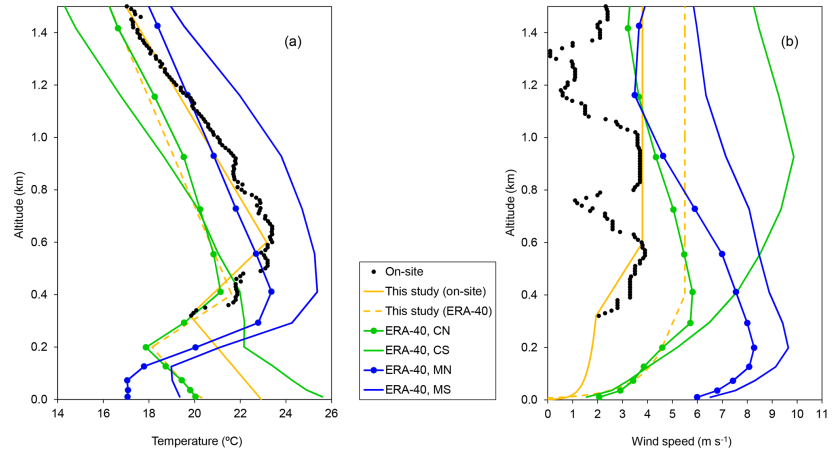

Figure 2. Vertical profiles of temperature and wind speed in the Quinault fire, measured on-site onboard the Convair aeroplane (black dots), at the four ERA-40 grid points closest to the fire (solid green lines for inland points and solid blue lines for marine points) and the two modelled profiles (solid and dashed orange lines). For the modelled profiles based on the ERA-40 analysed data (dashed orange line), we have applied the data at the northern inland point. Notation for the four grid points: $\mathrm{CN}$ - continental (i.e. inland), northern; CS - continental, southern; $\mathrm{MN}$ - marine, northern; MS marine, southern.

approximate distance of $120 \mathrm{~km}$ northeast from the fire (coordinates $48^{\circ} \mathrm{N}, 123^{\circ} \mathrm{W}$ ). We assumed tentatively that this site would be best representative of the fire site, as inland meteorological conditions would probably better represent the burn site than the marine ones.

The temperatures at the two continental points in the lowest atmospheric layers (below $200 \mathrm{~m}$ ) differ by approximately 4 to $6{ }^{\circ} \mathrm{C}$. There are also substantial differences in the wind speeds at these two points in higher atmospheric layers (above approximately $100 \mathrm{~m}$ ). The profiles of both temperature and wind speed at the two ERA-40 marine points show fairly similar characteristics to each other, both in terms of their overall shape and numerical values. The differences between the marine and inland profiles are substantial, both for temperature and wind speed. In conclusion, there is a substantial variation in both the temperature and wind speed profiles at the four considered ERA-40 points.

One could use either (i) the profiles analysed for the closest inland point, i.e. the $\mathrm{CN}$ point, or (ii) the interpolated profiles, based on the four closest points (or based only on the two inland points). An interpolation based on all the four points would result in a temperature profile that would be very slightly closer to the on-site measured profile, compared with the $\mathrm{CN}$ profile. However, in the case of the wind speed profile, the values at the ERA- $40 \mathrm{CN}$ point are clearly closest to the on-site measured meteorology; an interpolated profile (based on the data at either four or two stations) would be worse representative of the measured data. We have therefore simply used the profiles based on the data at the ERA- $40 \mathrm{CN}$ point in the following.

The relevant atmospheric stability parameters, such as the Monin-Obukhov length, are not given in the ERA- 
40 reanalysis data. We have therefore evaluated the Monin-Obukhov length at the ERA- $40 \mathrm{CN}$ point by using an approximate analytical method presented by Blümel (2000), which is based on a relationship between the stability parameter $\xi$ and the bulk Richardson number. The measured values of temperature and wind speed at two height levels were used as input values for this method. The roughness lengths of momentum and heat transfer were also evaluated based on the reported experimental data. The value of the inverse Monin-Obukhov length $L^{-1}$ was found to be equal to $-0.0015 \mathrm{~m}^{-1}$. This value corresponds to an approximately neutral, very slightly unstable atmospheric conditions.

In the case of on-site meteorological data, the relevant atmospheric stability parameters, such as the Monin-Obukhov length, are not reported in the original references (Kaufman et al., 1996; Hobbs et al., 1996). Trentmann et al. (2002) assumed a dry adiabatic lapse rate from the ground surface up to the height of $200 \mathrm{~m}$. This assumption is in agreement with the value of the Monin-Obukhov length mentioned above. For simplicity, we have assumed the adiabatic lapse rate up to the height of $320 \mathrm{~m}$ by matching this rate with the value measured at $320 \mathrm{~m}$. Wind speed below the height of $320 \mathrm{~m}$ was evaluated according to the Monin-Obukhov similarity profile.

According to both methods - the on-site measurements and the evaluations based on the data at the ERA- $40 \mathrm{CN}-$ there was an elevated inversion with a magnitude of about $3{ }^{\circ} \mathrm{C}$. This was located at the heights from approximately 320 to $600 \mathrm{~m}$ (with a lapse rate of $0.012^{\circ} \mathrm{C} \mathrm{m}^{-1}$ ) or from 200 to $400 \mathrm{~m}$ (with a lapse rate of $0.017^{\circ} \mathrm{C} \mathrm{m}^{-1}$ ) according to the modelled profiles fitted to the on-site and ERA-40 evaluations, respectively. This difference in the evaluated altitudes and lapse rates of the inversions could have a substantial influence on the modelled plume behaviour. As the plume will penetrate an inversion layer, the buoyancy of the modelled plume will be correspondingly decreased.

These two meteorological evaluations were also significantly different for the profiles of the wind speed, both regarding the original data and the modelled profiles fitted to the data. The wind speeds evaluated by ERA- 40 were substantially higher, compared with the on-site aeroplane data. If the horizontal wind speed is higher, the modelled plume trajectory will be more strongly bent to the wind direction.

The differences in the evaluations using the two methods are in part due to the limited spatial representativity of the ERA-40 data used. The selected data point is probably representative for more inland conditions, compared with the prescribed burning site.

\subsubsection{Evaluation of the source term for the dispersion computations}

Regarding input values of the BUOYANT model, we will need to know the following source properties: (i) convective energy release from the fire, (ii) the physical extent of the fire, and (iii) the fire temperature. Using the BUOYANT model, it can be shown by means of numerical simulations (not shown here) that the convective energy release is the most important source parameter in terms of the final plume rise.

Heat release rate over time for the Quinault burn was estimated by Hobbs et al. (1996) using the Emissions Production Model (EPM; Sandberg and Peterson, 1984). The EPM takes into account the loading, consumption, and moisture of different fuels and the duff (the latter is defined to be the decayed material on the forest floor), and also accounts for the different phases of the fire (flaming and smouldering). The EPM evaluates as model output, among other things, the total heat released per time (energy flux) by a fire. The model can be used for evaluating the time-dependent release of energy originating from the fire, and the emissions of fine particulate matter (aerodynamic diameter $<2.5 \mu \mathrm{m}$ ) and some trace gases $\left(\mathrm{CO}, \mathrm{CO}_{2}\right.$ and $\left.\mathrm{CH}_{4}\right)$.

The temporal maximum of the total heat release rate predicted by the EPM was about $6.5 \mathrm{GW}$ (Hobbs et al., 1996); this occurred at 13:05. However, only the convective energy release is needed for the buoyant plume computations (not the radiative contribution and the heat conduction to the ground). The fraction of the total energy released by combustion that is available for convection depends on the ambient and fuel conditions and is highly uncertain (Trentmann et al., 2006; Freitas et al., 2010). Commonly found estimates for the radiative energy are between nearly $0 \%$ (Wooster, 2002; Wooster et al., 2005) and 50\% (McCarter and Broido, 1965; Packham, 1969). These estimates are based on laboratory studies or small-scale fires, and their application to large-scale crown fires resulting in pyrocumulonimbus cloud (pyroCb) convection remains highly uncertain (Trentmann et al., 2006).

Trentmann et al. (2002) assumed that $55 \%$ of the total energy is available for convection for their simulation of the Quinault fire. The same fraction was chosen by Freitas et al. (2010) for two deforestation fires with sizes of 10 and 50 ha in the Amazon Basin. We have therefore multiplied the total heat release rate by a factor of 0.55 , which is simply in the middle of the commonly accepted range from 0.4 to 0.8 (Trentmann et al., 2002). Thus, for the BUOYANT model simulations we have selected the maximum convective heat flux, $3.6 \mathrm{GW}$, as input.

However, the maximum heat release rate probably occurred somewhat earlier, between 12:15 and 12:45, based on the estimates from ground observations of the ignition pattern and the plume. At that time, a maximum area was in combustion (Hobbs et al., 1996). Clearly, the evaluation of the optimally representative convective heat flux includes many uncertainties.

The Geostationary Operational Environmental Satellite (GOES)-8 Automated Biomass Burning Algorithm (ABBA) was used to estimate the average fire temperature range from 586 to $626 \mathrm{~K}$, from 12:45 to 14:32 (Menzel and Prins, 1996). We have selected the value of $600 \mathrm{~K}$ for the fire temperature. 


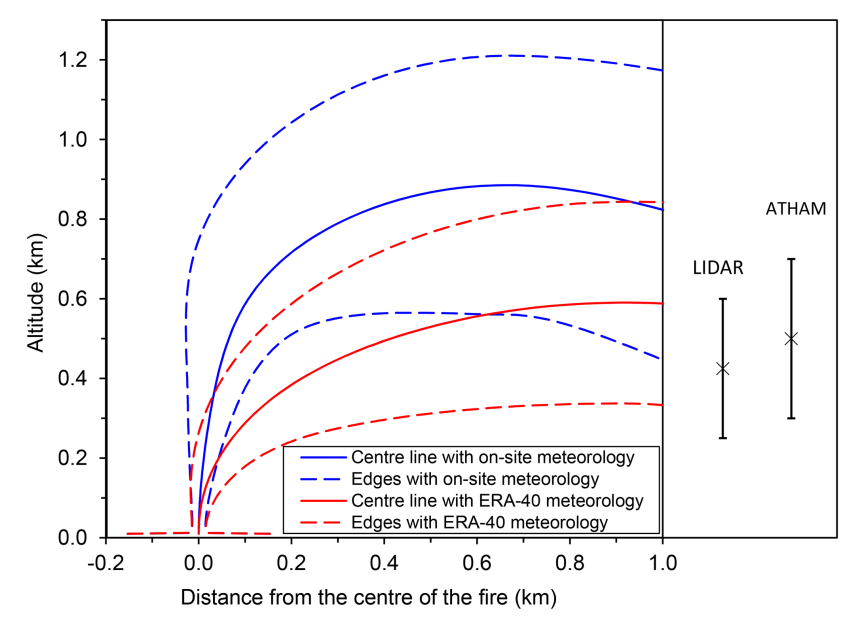

Figure 3. Simulated altitude of the centre line, and the lower and upper edges of the plume for the Quinault prescribed burn as a function of the downwind distance. The results are shown both for using (i) the meteorological measurements made on-site (blue solid and dashed lines, denoted "on-site meteorology") and (ii) the reanalysis of the meteorological observations (red solid and dashed lines, denoted "ERA-40 meteorology"). The vertical ranges of the previous results obtained using on-site lidar measurements ("LIDAR"; Trentmann et al., 2002) and computations using the ATHAM model (Trentmann et al., 2002) have also been presented.

The maximum fire size (during both flaming and smouldering) was evaluated to be about $0.17 \mathrm{~km}^{2}$, based on ground observations; this occurred at 12:15 (Menzel and Prins, 1996). We have selected this value $\left(0.17 \mathrm{~km}^{2}\right)$ for the source area.

\subsubsection{Comparison of the predictions of the BUOYANT model against observations and previous modelling studies}

The modelled altitudes of the plume centre line and the lower and upper boundaries of the plume have been presented in Fig. 3, applying both meteorological options. The lower and upper boundaries were defined to be equal to the distance from the plume centre line at which the concentration is $37 \%$ of the maximum concentration at the centre line of a Gaussian distribution (these correspond to a distance $\sigma$, defined in Appendix A). The plume has a substantially lower injection height and a shallower trajectory for the ERA-40 meteorology case compared with the on-site meteorology case. This is due both to (i) the lower estimated altitude of the inversion layer and (ii) the substantially higher estimated wind speeds for the ERA-40 case (cf. Fig. 2a and b). For the on-site meteorology case, the predicted maximum plume rise (injection height) is $670 \mathrm{~m}$; for the ERA-40 meteorology case, the maximum plume rise is $460 \mathrm{~m}$.

According to the computations with the BUOYANT model, the vertical extents of the plume (lower and upper edges) at the point of maximum plume rise were between 500 and $800 \mathrm{~m}$ (i.e. plume thickness is $300 \mathrm{~m}$ ) and between
200 and $700 \mathrm{~m}$ (plume thickness is $500 \mathrm{~m}$ ) for the on-site and ERA-40 meteorology cases, respectively. As there were substantial uncertainties both in the determination of the source properties and the relevant meteorological profiles, we have presented these values only at an accuracy of hundreds of metres.

Hobbs et al. (1996) determined the vertical distribution of smoke particles in the plume from lidar measurements onboard the Convair aeroplane. The observed injection heights of the aerosol particles ranged from 250 to $600 \mathrm{~m}$ according to Trentmann et al. (2002) (shown in Fig. 3). They concluded that the plume was about $400 \mathrm{~m}$ thick and that it ascended to an average height of about $350 \mathrm{~m}$ as it drifted downwind; the plume was observed to a distance of about $25 \mathrm{~km}$.

In the case of on-site meteorology, the BUOYANT model over-predicted the observations; however, this difference could also be caused by the uncertainties in evaluating the fire source term, especially the convective heat flux. There were also substantial differences of the results obtained using the two alternative meteorological data sets.

Other model evaluations have also been previously conducted based on the Quinault fire. Trentmann et al. (2002) simulated the dynamical evolution of the plume, using the active tracer high-resolution atmospheric model (ATHAM). They used as model input the on-site meteorological profiles and the evaluated heat emissions from the fire. Furthermore, they estimated the injection height of the aerosol particles to range from 300 to $700 \mathrm{~m}$ (cf. Fig. 3).

Freitas et al. (2007) applied a simple one-dimensional time-dependent entrainment plume model originally developed by Latham (1994) to estimate the plume rise associated with the Quinault prescribed fire. They evaluated that the plume reached a maximum height of about $600 \mathrm{~m}$.

\subsubsection{Comparison of the predictions of a semi-empirical model by Sofiev et al. (2012) with measurements}

The model of Sofiev et al. (2012) requires as input values the fire radiative power (FRP) of the source, the height of the top of the boundary layer $\left(H_{\mathrm{abl}}\right)$ and Brunt-Vaisala frequency in the free troposphere $\left(N_{\mathrm{FT}}\right)$. The evaluation of these input values is based on the data described above. The top of the plume height $H_{\mathrm{p}}$ is evaluated from

$H_{\mathrm{p}}=\alpha H_{\mathrm{abl}}+\beta\left(\frac{\mathrm{FRP}}{P_{f 0}}\right)^{\gamma} \exp \left(-\frac{\delta N_{\mathrm{FT}}^{2}}{N_{0}^{2}}\right)$,

where $\alpha=0.24, \quad \beta=170 \mathrm{~m}, \quad \gamma=0.35, \delta=0.6, \quad P_{f 0}=$ $10^{6} \mathrm{~W}$ and $N_{0}^{2}=2.4 \times 10^{-4} \mathrm{~s}^{-2}$ (Sofiev et al., 2012).

As FRP, similar to the sensible heat flux, was not measured directly, we had to assume that it is a certain fraction of the total heat release. Following Wooster et al. (2005), Ichoku and Kaufman (2005), Trentmann et al. (2002) and Sofiev et al. (2009), this fraction was assumed to be $40 \%$; however, the uncertainty of evaluating this fraction is substantial. The 
maximum FRP was therefore approximately 2.6 GW. Based on the temperature profile observations, assuming the profiles modelled in this study, $H_{\mathrm{abl}}=300 \mathrm{~m}$.

However, the evaluation of the Brunt-Vaisala frequency is unequivocal. In deriving Eq. (16), it was assumed that the stability in the free troposphere does not change substantially, which is not the case for the Quinault experiment. Inside the inversion layer, the Brunt-Vaisala frequency $N_{\mathrm{IL}}^{2}=7.8 \times$ $10^{-4} \mathrm{~s}^{-2}$, whereas above it, the Brunt-Vaisala frequency $N_{\mathrm{FT}}^{2}=2.5 \times 10^{-4} \mathrm{~s}^{-2}$. Strictly speaking, these conditions are not within the validity regime of Eq. (16). However, that it is the inversion that will mainly restrict the plume rise, not the overlaying layer. Using the value of $N_{\mathrm{IL}}$ instead of that of $N_{\mathrm{FT}}$ in Eq. (16) results in the top of the plume height being $H_{\mathrm{p}}=450 \mathrm{~m}$, whereas using the above-mentioned value of $N_{\mathrm{FT}}$ results in an unrealistic estimate, $H_{\mathrm{p}}=1.5 \mathrm{~km}$.

\subsection{The prescribed burning experiment in Hyytiälä}

\subsubsection{Evaluation of the vertical profiles of meteorological variables}

Meteorological measurements were carried out on-site at the burn area perimeter, and at the SMEAR II station located $400 \mathrm{~m}$ north of the burn area. The measurements at the burn area perimeter were done at a height of $10 \mathrm{~m}$ above ground, and the SMEAR II station measurements were done at various heights up to $73 \mathrm{~m}$ above ground. The aeroplane measurements were conducted at various heights, with the maximum height being about $2.5 \mathrm{~km}$. Measurements on particulate matter onboard the aeroplane indicated that at least part of the plume reached the altitude of approximately $1.8 \mathrm{~km}$ (Virkkula et al., 2014a).

The BUOYANT model requires data on the vertical meteorological profiles at least up to the height of the predicted plume rise. The measurements at the burn area perimeter and the SMEAR II station therefore do not provide sufficient information on the atmospheric vertical profiles. We have additionally applied the measured data from Jokioinen observatory, located approximately $120 \mathrm{~km}$ south-southwest of the burn area. Daily sounding data at the observatory of Jokioinen are available at 00:00 and 12:00 UTC.

The vertical wind speed and temperature profiles applied by the model are presented in Eqs. (3) and (4). As in the case of the Quinault experiment, we have evaluated the Monin-Obukhov length using the method presented by Blümel (2000), based on the sounding data at Jokioinen at 12:00 UTC. The estimated value, $L^{-1}=-0.0012 \mathrm{~m}^{-1}$, indicates a moderately unstable condition. Based on the potential temperature profile, the height of the ABL was estimated to be $2250 \mathrm{~m}$. The profiles of potential temperature and wind speed measured at Jokioinen and the modelled profiles are presented in Fig. 4a and b. The spatial representativity of these profiles is limited by the distance of observations from
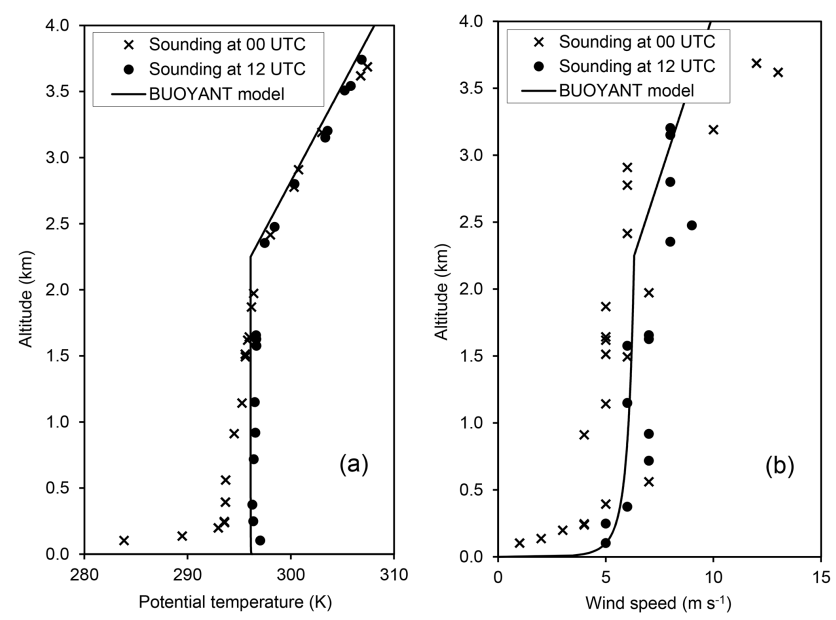

Figure 4. Vertical profiles of potential temperature and wind speed, both measured at the observatory of Jokioinen on 26 June 2009 at 00:00 and 12:00 UTC, and the modelled profiles at 12:00 UTC.

the burn site. The observatory of Jokioinen is located approximately $120 \mathrm{~km}$ south-southwest of the burn area.

Average measured horizontal wind speeds during the flaming phase at the SMEAR station were 0.55 and $2.2 \mathrm{~m} \mathrm{~s}^{-1}$ at the heights of 8.4 and $74 \mathrm{~m}$ above ground, respectively (Virkkula et al., 2014a). The wind speed was either light or it was a calm situation during most of the time in the course of the experiment. The corresponding maximum horizontal wind speeds were approximately 2 and $6 \mathrm{~m} \mathrm{~s}^{-1}$, respectively, measured at $1 \mathrm{~Hz}$ frequency. The BUOYANT-modelled wind speeds were 3.3 and $4.8 \mathrm{~m} \mathrm{~s}^{-1}$ at the heights of 8.4 and $74 \mathrm{~m}$ above ground, respectively.

\subsubsection{Evaluation of the source term for the dispersion computations}

All the time instants mentioned in the following refer to local time (i.e. UTC $+3 \mathrm{~h}$ ).

The convective heat flux can be determined based on Eqs. (1) and (2), provided that the initial vertical flow velocity, the fire temperature and the ambient temperature are known from measurements. The computed convective heat flux density during the flaming phase is presented in Fig. 5. The substantial temporal variability of the values is partly caused by the measurement set-up. The fire front advanced from the sides of the burn area towards its centre, where the sonic anemometer was located. The fire was close to the sensor several times: the first close passage occurred at 09:02-09:11, the second at 09:23-09:26 and the final passage at 09:35-09:52 (Virkkula et al., 2014a). After 10:02, the area around the sensor was burning more steadily but with a lower intensity. The intermittent negative heat flux densities were caused by downward flow velocities.

Regarding input for the plume rise modelling, we would ideally need spatially representative measurements of the fire 


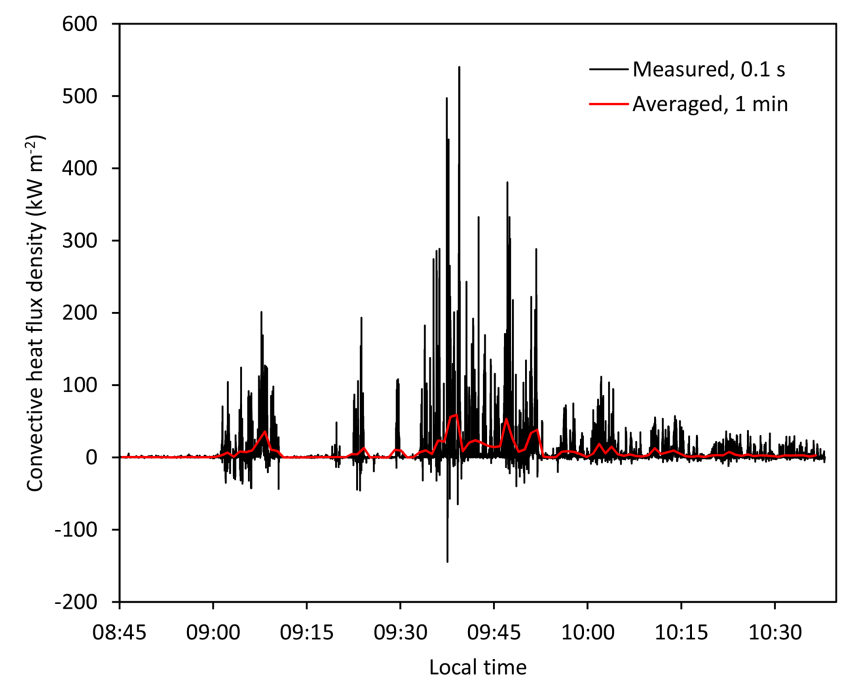

Figure 5. Computed convective heat flux density, determined from measurements during most of the flaming phase (black line). The measuring frequency was $10 \mathrm{~Hz}$. The $1 \mathrm{~min}$ average value of the convective heat flux density is also presented (red line).

temperature and vertical flow speed. This implies that the measurement site for these quantities should ideally be situated in the middle of the formed fire plume at all times. Clearly, this was not possible in the present experimental setup, as only one permanently positioned site was available in the middle of the burned area. A practical solution is to select as model input the maximum measured values of the fire temperature and vertical flow speed, either directly from the measured data or first using a selected temporal averaging of the measured data. A similar approach has also been used in the case of the Quinault fire in several previous studies (e.g. Trentmann et al., 2002), and in this study.

We have conducted the model simulations using several alternative heat flux values. We selected (i) the instantaneous maximum value (this will result in the highest plume rise) and (ii) the maximum value of the 1 min averages. An estimate of the source area can be made visually, both (i) based on the photographs taken from the fire and (ii) by analysing the measured soil temperatures. We evaluated a maximum source size to be half of the total burn area, i.e. $A=0.40$ ha. In order to evaluate the influence of inaccuracy of this estimate, results have also been computed by assuming a substantially smaller area, one-fifth of the total burned area. The assumed cases have been presented in Table 1 .

\subsubsection{Comparison of model results against observations}

The measurement data do not allow for us to directly estimate the final plume rise. However, the particle number concentration measurements onboard the aeroplane provide corresponding information on the ascent of the plume, which

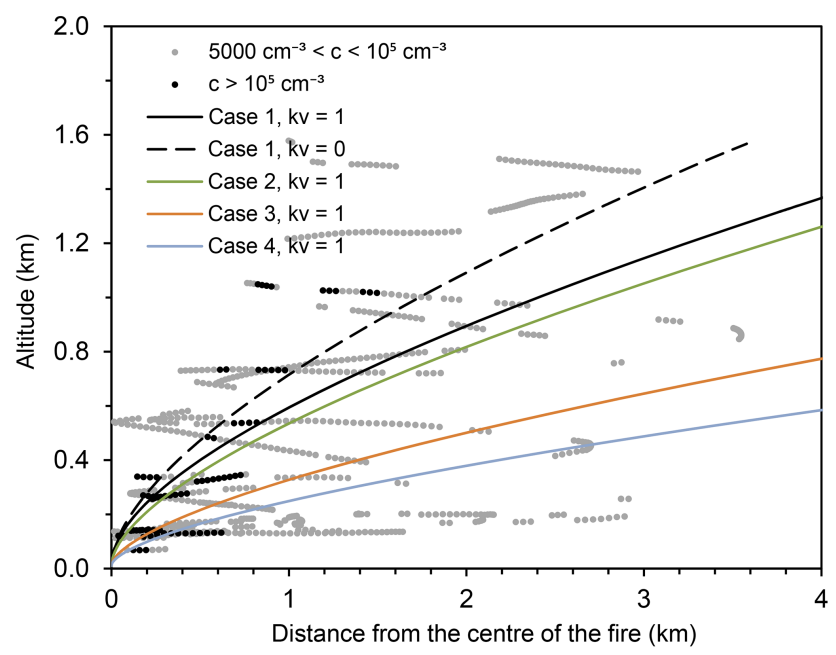

Figure 6. Total particle number concentrations measured on an aircraft in Hyytiälä during the flaming stage on 26 June 2009 (grey and black dots), and the predicted plume centre line trajectory for case 1 , assuming $k_{v}=1$ and $k_{v}=0$ (Eq. 11) (black solid and dashed lines), and cases $2-4$, assuming $k_{v}=1$ (green, orange and blue lines). The measured particle number concentrations $(c)$ have been classified into two separate categories: highest (black dots) and medium-high (grey dots) concentrations (the ranges are indicated in the figure caption). The particle number concentrations were determined for particles with an aerodynamical diameter larger than $3 \mathrm{~nm}$.

can be compared with the predicted centre line trajectory of the plume.

The measured particle number concentrations during the flaming phase (from 09:00 through 09:56), and the predicted trajectories of the plume for cases 1-4 have been presented in Fig. 6 . For case 1, we have computed the results by including and excluding the so-called added mass term in Eq. (11), i.e. $k_{v}=1$ and $k_{v}=0$, respectively. The aim of this sensitivity exercise was simply to find out the potential uncertainty that may be caused by the variation in this parameter. Excluding this term $\left(k_{v}=0\right)$ results in approximately $20 \%$ higher predicted plume altitude.

The spatial resolution of the aircraft-based measurements is limited by the lower limit of the aircraft speed. The ground speed of the aeroplane was in the range of 106 to $199 \mathrm{~km} \mathrm{~h}^{-1}$, yielding a horizontal spatial resolution of approximately $29-55 \mathrm{~m}$ for the measured airborne particle number concentration data (Virkkula et al., 2014a).

The predictions for cases 1 and 2 agree relatively better with the observations, compared with the predictions for cases 3 and 4 . The modelling for cases 3 and 4 substantially under-predicts the measured plume heights. One potential reason for this under-prediction could be an underestimated convective heat flux from the source. The measurement setup probably cannot provide for sufficiently representative values of the high temperatures and intensive vertical flows 
Table 1. The definition of the example cases selected for the prescribed burning experiment in Hyytiälä, and the computed convective heat fluxes $\left(Q_{\mathrm{c}}\right)$ for these cases. The computations were performed for the measured maximum values and for measured maximum values during $1 \mathrm{~min}$ for the fire temperatures $(T)$ and the measured vertical flow velocities $(v)$. For each averaging option, two alternative values were assumed for the measured active fire source areas $(A)$.

\begin{tabular}{llrrrr}
\hline Case number & Averaging of $T, v$ and $Q_{\mathrm{c}}$ & $T(\mathrm{~K})$ & $v\left(\mathrm{~m} \mathrm{~s}^{-1}\right)$ & $A(\mathrm{ha})$ & $Q_{\mathrm{c}}(\mathrm{MW})$ \\
\hline 1 & Instantaneous maximum & 370 & 7.3 & 0.40 & 2200 \\
2 & Instantaneous maximum & 370 & 7.3 & 0.16 & 870 \\
3 & Maximum during 1 min & 310 & 3.2 & 0.40 & 240 \\
4 & Maximum during 1 min & 310 & 3.2 & 0.16 & 95 \\
\hline
\end{tabular}

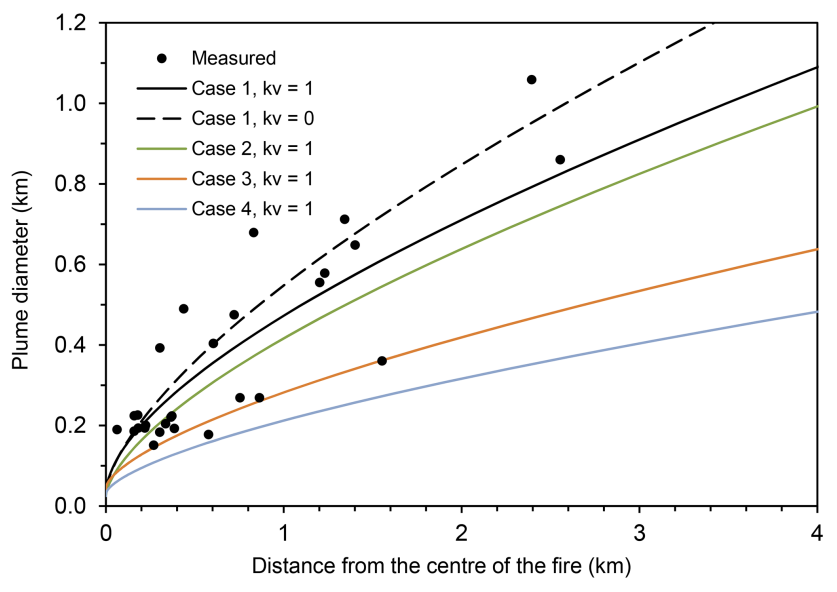

Figure 7. The measured and predicted plume diameters against downwind distance from the centre of the fire for cases $1-4$. The data of measurements are presented as black dots, and predictions as solid and dashed lines.

in the centre of the buoyant plume during most of the measuring time.

The measured and predicted plume diameters for cases 1-4 are presented in Fig. 7. For case 1, we have computed the diameters by including and excluding the so-called added mass term in Eq. (11). The measured plume widths were determined based on the measured particle number concentrations on the aeroplane. However, the uncertainty of the measured plume widths is substantial, caused by the limited spatial resolution, especially for the narrowest plumes.

The measured values were defined as the full plume width defined at half of the maximum concentrations (denoted here as FWHM). In more detail, the FWHM is defined as the horizontal distance between two points on a lateral spatial concentration profile, at which the function reaches half its maximum value (Virkkula et al., 2014a). The model assumes a top-hat profile, which has been converted into an equivalent Gaussian profile using the procedure described in Appendix A.

\subsubsection{Comparison of the predictions of the BUOYANT model with those of a semi-empirical model}

We applied Eq. (16) in the case of the prescribed burn at Hyytiälä. For the four cases defined in Table 1, we obtained the FRP values of 1600, 630, 180 and $69 \mathrm{MW}$, respectively. Based on the temperature profiles, $H_{\mathrm{abl}}=2300 \mathrm{~m}$ and $N_{\mathrm{FT}}=2.1 \times 10^{-4} \mathrm{~s}^{-2}$. In this case, there are no difficulties in estimating the $N_{\mathrm{FT}}$ value. Then the heights of the plume top will be $1.9,1.5,1.2$ and $1.0 \mathrm{~km}$ for cases $1-4$, respectively.

\section{Conclusions}

We have presented an overview of a mathematical model, BUOYANT, that was originally designed for conditions of very high buoyancy, such as what might be found in a toxic plume above a major warehouse fire. The model addresses the cross-plume integrated properties of a buoyant plume in the presence of a vertically varying atmosphere, including possibly occurring inversion layers. We have compared the model predictions with the data of two well-reported prescribed wild-land fire experiments.

The model does not contain any free parameters, and was not adjusted to the measured data. We have used the values of three model parameters, the entrainment coefficients $\left(\alpha_{1}\right.$, $\alpha_{2}$ ) and the factor $k_{v}$ in the equation for the rate of vertical momentum flux, which were previously determined based on a comparison of model predictions and wind tunnel observations (Liedtke and Schatzmann, 1997; Kukkonen et al., 2000).

The presented comparison of model predictions with the data of two atmospheric dispersion cases provided some information on the potential capabilities of the model, but cannot be considered as a conclusive model evaluation. The reason for this is that there are several major challenges in determining the source properties and the meteorological conditions in such field experiments.

There were substantial differences between the two considered prescribed burning experiments. The burned area in the Quinault experiment was substantially larger, approximately 20 ha, compared with that in the Hyytiälä experiment, 0.8 ha. Correspondingly, the maximum convective heat 
flux in the Quinault experiment, 3.6 GW, was clearly higher than that in the Hyytiälä experiment, $0.2 \mathrm{GW}$ (the latter reported here as $1 \mathrm{~min}$ maximum). The meteorological conditions were also substantially different in these two experiments; there was an elevated inversion in the case of the Quinault experiment. The plume in the Hyytiälä experiment ascended to higher altitudes compared with that in the Quinault experiment, according to both the measurements and the model predictions. This was mainly caused by the different vertical structure of the atmosphere, especially the temperature inversion in the Quinault case.

For the SCAR-C experiment in Quinault (US) in 1994, the predicted vertical extents of the plume at the point of maximum plume rise were between 500 and 800 and between 200 and $700 \mathrm{~m}$ for the on-site and ERA-40 meteorology cases, respectively. The observed injection heights of the aerosol particles based on airborne lidar measurements ranged from 250 to $600 \mathrm{~m}$ according to Trentmann et al. (2002). Hobbs et al. (1996) evaluated that the plume ascended to an average height of about $350 \mathrm{~m}$ and was about $400 \mathrm{~m}$ thick. However, there were substantial uncertainties in the model input data. There were substantial differences of the results obtained using two alternative meteorological data sets; this demonstrates the challenges of accurately evaluating the relevant vertical atmospheric profiles.

The BUOYANT model can naturally allow for the variation in the vertical meteorological profiles and, in particular, the influence of the temperature inversions. However, the semi-empirical model of Sofiev et al. (2012) does not have a treatment for low-level inversions. Strictly speaking, it is therefore not applicable in the Quinault case. However, a qualitative agreement between the predictions of this model and measurements was achieved when the stratification of the inversion layer was taken into account (i.e. the use of $N_{\mathrm{IL}}$ instead of $N_{\mathrm{FT}}$ ).

For the prescribed burning experiment in Hyytiälä (Finland) in 2009, the model predictions were compared with plume elevations and diameters, determined based on number concentration measurements of particulate matter onboard an aeroplane. Using maximum measured values of the fire temperature and vertical flow speed as model input values resulted in a relatively better agreement between modelled and measured results regarding both the plume trajectories and their diameters. We also numerically evaluated the influence of a maximum variation in one important parameter, the factor $k_{v}$, in the equation for the rate of vertical momentum flux. Its influence was found to be noticeable, but not dominant, for the overall results.

There were substantial uncertainties in estimating the source terms for the atmospheric dispersion computations, for both of the addressed prescribed burning experiments. With regard to input values of the plume rise models, we will need to know at least the convective energy release from the fire and the physical extent of the fire. However, the evaluation of the optimally representative convective heat flux includes many uncertainties. For instance, it is generally not possible to conduct spatially representative measurements of the fire temperatures and vertical flow velocities in the middle of the fire plume continuously throughout the development of a major fire.

The source term data that are needed as input values for plume rise models could be determined in at least the following ways:

(1) by using the measured or estimated fire temperatures, vertical velocities and areas of fire;

(2) based on estimates of the total amount of the burned material;

(3) based on remote sensing (commonly satellite) data;

(4) utilizing a fire emission model.

In this study, we used method 1 for the Hyytiälä fire, and method 4 for the Quinault fire (i.e. the predictions of the EPM).

Each of the above-mentioned methods has advantages and limitations. An advantage of method 1 is that it is a direct method, and its accuracy depends mainly on the representativity of the measurements conducted. A limitation is that it is challenging to measure those quantities continuously in the middle of an intensive fire. An advantage of method 2 is that the amount of material before and after the burn can be evaluated fairly accurately. A limitation is that this method does not yield any information of the temporal development of the source term. One of the main advantages of satellite measurements (method 3$)$ is a wide spatial coverage. A limitation is that relatively smaller fires (such as the Hyytiälä prescribed burn) cannot be detected at all from satellites. Advantages of using fire emissions models (method 4) include that, at least in principle, detailed properties of the evolution of the fire can be taken into account. Clearly, the predicted fire source term is dependent both on the accuracy of input data used by the fire emission model and the properties of the fire emission model itself. In an acute emergency situation, the main issue is simply the availability of data or estimated values regarding the fire. Most likely, methods 1 and 2 would be most quickly applicable.

Clearly, there are also uncertainties in the modelling of the plume rise and dispersion. In particular, we have selected to use the form of the entrainment terms according to Ricou and Spalding (1961), instead of the alternative formulation of Morton et al. (1956). However, there is no convincing theoretical or experimental evidence regarding which of these models would be preferable in the case of strongly buoyant plume dispersion.

Approximating the fire as a simple circular source (as in the model) may not be appropriate; this depends on the distribution of the fire across the landscape, particularly in areas of complex terrain. The convective heat release can also be 
unevenly distributed across the landscape (e.g. Liu et al., 2010; Achtemeier et al., 2012).

The BUOYANT model contains three numerical parameters that have to be determined based on experimental results (two entrainment coefficients and the $k_{v}$ factor). We have determined the two plume entrainment coefficients based on wind tunnel measurements by Liedtke and Schatzmann (1997). However, it has not been conclusively shown that the adopted values would be the optimal ones in the case of major fires in various atmospheric conditions. The model also assumes a steady state, and it does not allow for directional wind shear. The current version of the model assumes a dry atmosphere. However, the condensation and evaporation of water may possibly play a significant role in plume rise analyses (e.g. Freitas et al., 2007). 
Appendix A: Conversion of the top-hat profile of the concentration to an equivalent Gaussian profile

Integral models of buoyant plumes assume that the plume can be described by bulk representations of the flow, varying with distance along the plume centre line, such as plume velocity, density, concentration and other properties. Martin et al. (1997) examined the possible existence of a buoyant plume to have a self-similar flow. A field $\varphi$ (velocity, density, etc.) is defined here to be self-similar if it is separable in the form

$\varphi(s, r)=\varphi_{s}(s) \varphi_{r}(r)$

where $s$ is the distance along the plume centre line and $r$ is the radial distance from the centre of the plume. Martin et al. (1997) concluded that, in principle, the three-dimensional Reynolds equations (reduced to two dimensions by the assumption of cylindrical symmetry) have a limited form of self-similarity. Self-similar solutions may be a reasonable expectation in many cases, but only after some specified distance from source (Fanneløp and Webber, 2003).

For simplicity, let us first assume an isothermal plume, i.e. the temperature outside of the plume is the same as the temperature within the plume. Let us also assume that wind speed is the only atmospheric property that varies with height. We assume a Gaussian distribution for concentration and wind speed inside the plume of the form

$c(s, r)=c_{S}(s) e^{-\left(r / R_{S}\right)^{2}}$,

$u(s, r)=u_{s}(s) e^{-\lambda\left(r / R_{S}\right)^{2}}$,

where $R_{S}$ is the Gaussian radius of the plume and the factor $\lambda$ allows for the concentration and wind speed profiles to have different Gaussian radii. Martin et al. (1997) provided an analytical solution for $c_{S}, R_{S}$ and $u_{s}$ in terms of the plume top-hat quantities.
However, for a more realistic non-isothermal plume within varying atmosphere, it is not possible for the concentration and excess temperature and density to all be self-similar (Martin et al., 1997, p. 179). Our procedure here is therefore to apply a simpler method, suitably modified from the method presented in Jagger (1983), where only the radial concentration distribution has a Gaussian distribution (all other fields are assumed to have a top-hat profile). The radial concentration distribution is then given by

$c(s, r)=c_{\mathrm{g}}(s) e^{-(r / \sigma)^{2}}$,

where $c_{\mathrm{g}}$ is the maximum concentration of the Gaussian distribution and $\sigma$ is a measure of the plume width where the concentration is $e^{-1} \approx 37 \%$ of its centre line (maximum) value.

The top-hat radius $(R)$ of the plume is defined by $10 \%$ of the peak Gaussian concentration distribution, i.e. $\sigma^{2}=$ $R^{2} / \ln (10)$. Half of the maximum Gaussian concentration therefore occurs at

$r=\sqrt{\frac{\ln (2)}{\ln (10)}} R \approx 0.55 R$.

The maximum concentration of the Gaussian distribution can be determined by equating the radially integrated top-hat and Gaussian distributions from zero to infinity (i.e. conserving the mass flux), yielding

$c_{\mathrm{g}}(s)=\sqrt{\frac{\ln \left(10^{4}\right)}{\pi}} c_{\mathrm{m}}(s) \approx 1.71 c_{\mathrm{m}}(s)$,

where $c_{\mathrm{m}}(s)$ is the top-hat concentration. 


\section{Code availability}

The source code that describes the near- and intermediatefield dispersion of a highly buoyant plume is available upon request from the authors. This code is written in Fortran 2003. With minor modifications, the code can also be used with a Fortran 95 compiler supporting the enhanced data type facilities (ISO/IEC, 1998).

Acknowledgements. We wish to thank Jörg Trentmann of the Deutscher Wetterdienst for the availability of the measured data onboard the Convair aeroplane. Support through the Academy of Finland projects ASTREX and APTA, as well as through the FP7 projects TRANSPHORM and PEGASOS, is acknowledged.

Edited by: A. Kerkweg

\section{References}

Achtemeier, G. L., Goodrick, S. A., and Liu, Y.,: Modeling multiple-core updraft plume rise for an aerial ignition prescribed burn by coupling daysmoke with a cellular automata fire model, Atmosphere, 3, 352-376, doi:10.3390/atmos3030352, 2012.

Beljaars, A. C. M. and Holtslag, A. A. M.: Flux parameterization over land surfaces for atmospheric models, J. Appl. Meteorol., 30, 327-341, 1991.

Blümel, K.: An approximate analytical solution of flux-profile relationships for the atmospheric surface layer with different momentum and heat roughness lengths, Bound.-Lay. Meteorol., 97, 251-271, 2000.

Briggs, G. A.: Plume rise predictions, in: Lectures on Air Pollution and Environmental Impact Analyses, edited by: Haugen, D. A., American Meteorological Society, Boston, 59-111, 1975.

Brutsaert, W.: Evaporation Into the Atmosphere, D. Riedel Publishing Company, Dordrecht, 299 pp., 1982.

Davison, P. S.: Estimating the direct radiative forcing due to haze from the 1997 forest fires in Indonesia, J. Geophys. Res., 109, 1-12, 2004.

Devenish, B. J., Rooney, G. G., Webster, H. N., and Thomson, D. J.: The entrainment rate for buoyant plumes in a crossflow, Bound.Lay. Meteorol., 134, 411-439, 2010.

Diner, D. J., Beckert, J. C., Reilly, T. H., Bruegge, C. J., Conel, J. E., Kahn, R. A., Martonchik, J. V., Ackerman, T. P., Davies, R., Gerstl, S. A. W., Gordon, H. R., Muller, J.-P., Myneni, R. B., Sellers, P. J., Pinty, B., and Verstraete, M. M.: Multi-angle Imaging SpectroRadiometer (MISR) instrument description and experiment overview, IEEE T. Geosci. Remote, 36, 1072-1087, 1998.

ERA 40: Daily Fields: available at: http://data-portal.ecmwf.int/ data/d/era40_daily/, last access: 29 October 2013.

Fanneløp, T. K. and Webber, D. M.: On buoyant plumes rising from area sources in a calm environment, J. Fluid Mech., 497, 319-334, 2003.

Fisher, B. E. A., Metcalfe, E., Vince, I., and Yates, A.: Modelling plume rise and dispersion from pool fires, Atmos. Environ., 35, 2101-2110, 2001.

Forster, C., Wandinger, U., Wotawa, G., James, P., Mattis, I., Althausen, D., Simmonds, P., O’Doherty, S., Jennings, S. G.,
Kleefeld, C., Schneider, J., Trickl, T., Kreipl, S., Jäger, H., and Stohl, A.: Transport of boreal forest fire emissions from Canada to Europe, J. Geophys. Res., 106, 22887-22906, 2001.

Freitas, S. R., Longo, K. M., Chatfield, R., Latham, D., Silva Dias, M. A. F., Andreae, M. O., Prins, E., Santos, J. C., Gielow, R., and Carvalho Jr., J. A.: Including the sub-grid scale plume rise of vegetation fires in low resolution atmospheric transport models, Atmos. Chem. Phys., 7, 3385-3398, doi:10.5194/acp-7-3385-2007, 2007.

Freitas, S. R., Longo, K. M., Trentmann, J., and Latham, D.: Technical Note: Sensitivity of 1-D smoke plume rise models to the inclusion of environmental wind drag, Atmos. Chem. Phys., 10, 585-594, doi:10.5194/acp-10-585-2010, 2010.

Garratt, J. R.: The atmospheric boundary layer, Cambridge University Press, Cambridge, 316 pp., 1994.

Gassó, S. and Hegg, D. A.: Comparison of columnar aerosol optical properties measured by the MODIS airborne simulator with in situ measurements: a case study, Remote Sens. Environ., 66, 138-152, 1998.

Gear, C. W.: Numerical initial value problems in ordinary differential equations, Prentice-Hall, Inc. Englewood Cliffs, New Jersey, 253 pp., 1971.

Hari, P. and Kulmala, M.: Station for measuring ecosystematmosphere relations (SMEAR II), Boreal Environ. Res., 10, 315-322, 2005.

Hobbs, P. V., Reid, J. S., Herring, J. A., Nance, J. D., Weiss, R. E., Ross, J. L., Hegg, D. A., Ottmar, R. D., and Liousse, C.: Particle and trace-gas measurements in the smoke from prescribed burns of forest products in the Pacific Northwest, in: Biomass Burning and Global Change, edited by: Levine, J. S., MIT Press, Cambridge, MA, 697-715, 1996.

Ichoku, C. and Kaufman, Y. J.: A method to derive smoke emission rates from MODIS fire radiative energy measurements, IEEE T. Geosci. Remote, 43, 2636-2649, 2005.

ISO/IEC: Information technology - Programming languages - Fortran - Enhanced data type facilities, Technical Report ISO/IEC 15581:1998, 1998.

Jagger, S. F.: Development of CRUNCH: A dispersion model for continuous releases of denser-than-air vapour into the atmosphere, UKAEA Report SRD R 229, Safety and Reliability Directorate, Warrington, 26 pp. + app., 1983.

Jirka, G. H.: Integral model for turbulent buoyant jets in unbounded stratified flows, Part I: Single round jet, Environ. Fluid Mech., 4, 1-56, 2004.

Kahn, R. A., Chen, Y., Nelson, D. L., Leung, F.-Y., Li, Q., Diner, D. J., and Logan, J. A.: Wildfire smoke injection heights: Two perspectives from space, Geophys. Res. Lett., 35, 4-7, doi:10.1029/2007GL032165, 2008.

Kaufman, Y. J., Remer, L. A., Ottmar, R. D., Ward, D. E., Li, R.R., Kleidman, R., Fraser, R. S., Flynn, L., McDougal, D., and Shelton, G.: Relationship between remotely sensed fire intensity and rate of emission of smoke: SCAR-C experiment, in: Biomass Burning and Global Change, edited by: Levine, J. S., MIT Press, Cambridge, MA, 685-696, 1996.

Kukkonen, J., Nikmo, J., Ramsdale, S. A., Martin, D., Webber, D. M., Schatzmann, M., and Liedtke, J.: Dispersion from strongly buoyant sources, in: Air Pollution Modeling and its Application XIII, edited by: Gryning, S.-E. and Batchvarova, E., Kluwer Academic/Plenum Publishers, 539-547, 2000. 
Kulmala, M., Asmi, A., Lappalainen, H. K., Carslaw, K. S., Pöschl, U., Baltensperger, U., Hov, Ø., Brenquier, J.-L., Pandis, S. N., Facchini, M. C., Hansson, H.-C., Wiedensohler, A., and O'Dowd, C. D.: Introduction: European Integrated Project on Aerosol Cloud Climate and Air Quality interactions (EUCAARI) - integrating aerosol research from nano to global scales, Atmos. Chem. Phys., 9, 2825-2841, doi:10.5194/acp-9-2825-2009, 2009.

Latham, D.: PLUMP: A one-dimensional plume predictor and cloud model for fire and smoke managers, General Technical Report INT-GTR-314, Intermountain Research Station, USDA Forest Service, 15 pp., 1994.

Liedtke, J. and Schatzmann, J.: Dispersion of plumes from strongly buoyant sources, Final Report to EC under contract EV5V-CT930262, 125 pp., 1997.

Liousse, C., Penner, J. E., Chuang, C., Walton, J. J., Eddleman, H., and Cachier, H.: A global three-dimensional model study of carbonaceous aerosols, J. Geophys. Res., 101, 19411-19432, 1996.

Liu, Y., Achtemeier, G. L., Goodrick, S. L., and Jackson, W.: Important parameters for smoke plume rise simulation with Daysmoke, Atmos. Pollut. Res. 1, 250-259, doi:10.5094/APR.2010.032, 2010.

Martin, D., Webber, D. M., Jones, S. J., Underwood, B. Y., Tickle, G. A., and Ramsdale, S. A.: Near- and intermediate-field dispersion from strongly buoyant sources, AEA Technology Report AEAT/1388, Warrington, 277 pp., 1997.

Mazzoni, D., Logan, J. A., Diner, D., Kahn, R., Tong, L., and Li, Q.: A data-mining approach to associating MISR smoke plume heights with MODIS fire measurements, Remote Sens. Environ., 107, 138-148, 2007.

McCarter, R. J. and Broido, A.: Radiative and convective energy from wood crib fires, Pyrodynamics, 2, 65-85, 1965.

Menzel, W. P. and Prins, E. M.: Monitoring biomass burning with the new generation of geostationary satellites, in: Biomass Burning and Global Change, edited by: Levine, J. S., MIT Press, Cambridge, MA, 56-64, 1996.

Middleton, J. H.: The rise of forced plumes in a stably stratified crossflow, Bound.-Lay. Meteorol., 36, 187-199, 1986.

Morton, B. R., Taylor, G., and Turner, J. S.: Turbulent gravitational convection from maintained and instantaneous sources, P. Roy. Soc. A, 234, 1-23, 1956.

Nikmo, J., Tuovinen, J.-P., Kukkonen, J., and Valkama, I.: A hybrid plume model for local-scale dispersion, Publications on Air Quality 27, Finnish Meteorological Institute, Helsinki, 65 pp., 1997.

Nikmo, J., Tuovinen, J. P., Kukkonen, J., and Valkama, I.: A hybrid plume model for local-scale atmospheric dispersion, Atmos. Environ., 33, 4389-4399, 1999.

Olesen, H. R.: Datasets and protocol for model validation, Int. J. Environ. Pollut., 5, 693-701, 1995.

Packham, D. R.: Heat transfer above a small ground fire, Aust. Forest Res., 5, 19-24, 1969.

Paulson, C. A.: The mathematical representation of wind speed and temperature profiles in the unstable atmospheric surface layer, J. Appl. Meteorol., 9, 857-861, 1970.

Ramsdale, S. A., Martin, D., Nikmo, J., Kukkonen, J., Liedtke, J., and Schatzmann, M.: Dispersion from strongly buoyant sources - overall executive summary, AEA Technology Report AEAT/1408, Warrington, 16 pp., 1997.
Ricou, F. P. and Spalding, D. B.: Measurement of entrainment by axisymmetrical turbulent jets, J. Fluid Mech., 11, 21-32, 1961.

Sandberg, D. V. and Peterson, J.: A source strength model for prescribed fire in coniferous logging slash, in: Proceedings of the 21st annual meeting of the Air Pollution Control Association, 12-14 November 1984, Portland, Oregon, 10 pp., 1984.

Schobesberger, S., Väänänen, R., Leino, K., Virkkula, A., Backman, J., Pohja, T., Siivola, E., Franchin, A., Mikkilä, J., Paramonov, M., Aalto, P. P., Krejci, R., Petäjä, T., and Kulmala, M.: Airborne measurements over the boreal forest of southern Finland during new particle formation events in 2009 and 2010, Boreal Environ. Res., 18, 145-163, 2013.

SLATEC: Common Mathematical Library, available at: http://www. netlib.org/slatec/index.html (last access: 29 October 2013), 1993.

Sofiev, M., Vankevich, R., Lotjonen, M., Prank, M., Petukhov, V., Ermakova, T., Koskinen, J., and Kukkonen, J.: An operational system for the assimilation of the satellite information on wildland fires for the needs of air quality modelling and forecasting, Atmos. Chem. Phys., 9, 6833-6847, doi:10.5194/acp-9-68332009, 2009.

Sofiev, M., Ermakova, T., and Vankevich, R.: Evaluation of the smoke-injection height from wild-land fires using remote-sensing data, Atmos. Chem. Phys., 12, 1995-2006, doi:10.5194/acp-12-1995-2012, 2012.

Trentmann, J., Andreae, M. O., Graf, H.-F., Hobbs, P. V., Ottmar, R. D., and Trautmann, T.: Simulation of a biomass-burning plume: Comparison of model results with observations, J. Geophys. Res., 107, AAC5.1-AAC5.15, doi:10.1029/2001JD000410, 2002.

Trentmann, J., Luderer, G., Winterrath, T., Fromm, M. D., Servranckx, R., Textor, C., Herzog, M., Graf, H.-F., and Andreae, M. O.: Modeling of biomass smoke injection into the lower stratosphere by a large forest fire (Part I): reference simulation, Atmos. Chem. Phys., 6, 5247-5260, doi:10.5194/acp-65247-2006, 2006.

Uppala, S. M., Kållberg, P. W., Simmons, A. J., Andrae, U., Da Costa Bechtold, V., Fiorino, M., Gibson, J. K., Haseler, J., Hernandez, A., Kelly, G. A., Li, X., Onogi, K., Saarinen, S., Sokka, N., Allan, R. P., Andersson, E., Arpe, K., Balmaseda, M. A., Beljaars, A. C. M., Van De Berg, L., Bidlot, J., Bormann, N., Caires, S., Chevallier, F., Dethof, A., Dragosavac, M., Fisher, M., Fuentes, M., Hagemann, S., Hólm, E., Hoskins, B. J., Isaksen, L., Janssen, P. A. E. M., Jenne, R., McNally, A. P., Mahfouf, J.-F., Morcrette, J.-J., Rayner, N. A., Saunders, R. W., Simon, P., Sterl, A., Trenberth, K. E., Untch, A., Vasiljevic, D., Viterbo, P., and Woollen, J.: The ERA-40 re-analysis, Q. J. Roy. Meteorol. Soc., 131, 2961-3012, 2005.

van Ulden, A. P. and Holtslag, A. A. M.: Estimation of atmospheric boundary layer parameters for diffusion applications, J. Clim. Appl. Meteorol., 24, 1196-1207, 1985.

Virkkula, A., Levula, J., Pohja, T., Aalto, P. P., Keronen, P., Schobesberger, S., Clements, C. B., Pirjola, L., Kieloaho, A.-J., Kulmala, L., Aaltonen, H., Patokoski, J., Pumpanen, J., Rinne, J., Ruuskanen, T., Pihlatie, M., Manninen, H. E., Aaltonen, V., Junninen, H., Petäjä, T., Backman, J., Dal Maso, M., Nieminen, T., Olsson, T., Grönholm, T., Aalto, J., Virtanen, T. H., Kajos, M., Kerminen, V.-M., Schultz, D. M., Kukkonen, J., Sofiev, M., De Leeuw, G., Bäck, J., Hari, P., and Kulmala, M.: Prescribed burning of logging slash in the boreal forest of Finland: emis- 
sions and effects on meteorological quantities and soil properties, Atmos. Chem. Phys., 14, 4473-4502, doi:10.5194/acp-14-44732014, 2014a.

Virkkula, A., Pohja, T., Aalto, P. P., Keronen, P., Schobesberger, S., Clements, C. B., Petäjä, T., Nikmo, J., and Kulmala, M.: Airborne measurements of aerosols and carbon dioxide during a prescribed fire experiment at a boreal forest site, Boreal Environ. Res., 19, 153-181, 2014b.

Wigley, T. M. L. and Slawson, P. R.: On the condensation of buoyant, moist, bent-over plumes, J. Appl. Meteorol., 10, 253-259, 1971.
Wooster, M. J.: Small-scale experimental testing of fire radiative energy for quantifying mass combusted in natural vegetation fires, Geophys. Res. Lett., 29, 2027, doi:10.1029/2002GL015487, 2002.

Wooster, M. J., Roberts, G., Perry, G. L. W., and Kaufman, Y. J.: Retrieval of biomass combustion rates and totals from fire radiative power observations: FRP derivation and calibration relationships between biomass consumption and fire radiative energy release, J. Geophys. Res., 110, D24311, doi:10.1029/2005JD006318, 2005. 